\title{
O SOCIOGRAMA E OS PROCESSOS GRUPAIS: UMA EXPERIÊNCIA NO CAMPO EDUCACIONAL
}

\author{
THE SOCIOGRAM AND GROUP PROCESSES: \\ AN EXPERIENCE IN EDUCATIONAL FIELD
}

\author{
EL SOCIOGRAMA Y LOS PROCESOS GRUPALES: \\ UNA EXPERIENCIA EN EL CAMPO EDUCACIONAL
}

\author{
Aurino Lima Ferreira ${ }^{\mathrm{I}}$ \\ TATIANA LIMA BRASIL ${ }^{\text {II }}$ \\ Nadja Maria AcIOLY-RèGnier ${ }^{I I I}$
}

\begin{abstract}
Resumo Esta pesquisa objetivou apresentar os deslocamentos grupais vivenciados por quatorze adolescentes que faziam parte de uma experiência educativa que buscava promover o desenvolvimento de relações interpessoais. Por meio de sociogramas, indicamos o lugar que cada participante ocupou dentro do grupo; os líderes e as configurações de subgrupos, isolados, periféricos e solitários que se formaram na sua constelação antes e após a intervenção. Apontamos um aumento das relações congruentes no espaço grupal, sugerindo uma melhoria das relações grupais. $\mathrm{O}$ uso do sociograma pode fornecer elementos para o planejamento de intervenções com vistas à melhoria na qualidade das relações interpessoais no campo educacional.

Palavras-chave: Sociograma; Grupo; Educação.
\end{abstract}

\begin{abstract}
This research aimed to present the group displacements experienced by fourteen adolescents who were part of an educational experience that sought to promote the development of interpersonal relationships. Through sociograms, we indicate the place that each participant occupied within the group, besides the leaders and configurations of isolated, peripheral, and solitary subgroups that were formed in their constellation before and after the intervention. We point out an increase of congruent relationships in group space,
\end{abstract}

I Universidade Federal de Pernambuco (UFPE), Recife/PE - Brasil.

II Doutoranda da Universidade Federal de Pernambuco (UFPE), Recife/PE - Brasil.

III ESPE Université Lyon1, Lyon - França. 
suggesting an improvement in group relationships. The use of the sociogram may provide elements for the planning of interventions aimed at improving the quality of interpersonal relationships in the educational field.

Key-words: Sociogram; Group; EduCATION.

RESUMEN Esta investigación objetivó presentar los descentramientos grupales vivenciados por catorce adolescentes participantes de una experiencia educativa que buscaba promover el desarrollo de relaciones interpersonales. A través de sociogramas, señalamos el lugar que cada participante ocupó dentro del grupo; los líderes y las configuraciones de subgrupos, aislados, periféricos y solitarios que se formaron en su constelación antes y después de la intervención. Se observa un aumento de relaciones coherentes en el espacio grupal, sugiriendo una mejora de las relaciones grupales. El uso del sociograma puede proporcionar elementos para la planificación de intervenciones que pretenden mejorar la calidad de las relaciones interpersonales en el campo educativo.

Palabras clave: Sociograma; Grupo; Educación.

\section{INTRODUÇÃo}

No cenário atual, o campo educacional enfrenta o desafio de lidar com situações que extrapolam o âmbito da mera apreensão de conteúdos, sendo convidado a pensar caminhos de formação humana (CUNHA, 2017; SEVERINO; BAUER, 2016; FREITAS, 2005,RODRIGUES, 2001)capazes de ajudar a compreender o manejo das relações interpessoais. Tais caminhos promovem um debate-reflexivo, no intuito de problematizar o crescente aumento de impasses e desafios nos relacionamento pessoais e sociais dentro dos espaços educativos (entre professores e alunos, alunos e alunos, professores e professores, direção e professores, direção e alunos etc.)

O trabalho grupal como espaço de pesquisa dos processos de humanização compõe uma longa tradição nos estudos da Psicologia. Isto vai desde os trabalhos iniciais de Freud (1976) até os metódicos experimentos de Kurt Lewin (1989), os grupos de encontro de Carl Rogers (1978). Contudo, há ainda uma escassez de reflexões sobre esses processos no campo educacional. Em uma revisão sistemática da literatura acerca das relações interpessoais no ambiente escolar, Macedo e Medina $(2017$, p. 109) apontaram a pouca quantidade de estudos nessa área e hipotetizaram que ela:

[...] ainda não é amplamente conhecida pelos professores, ou não é valorizada pelos pesquisadores. Apesar disso, reitera-se a importância da divulgação dessa área do conhecimento, pois a promoção de Habilidades Sociais dentro do contexto educacional é exemplo de um trabalho que pode ser utilizado como forma de prevenção e deve ser mais valorizado pelos profissionais.

Os estudos Vieira-Santos, Del Prette e Del Prette (2018) e Del Prette e Del Prette $(2008,2001)$ são pioneiros, ao indicarem o desenvolvimento de habilidades que melhoram 
as interações sociais como um elemento fundamental para a construção de relações interpessoais mais satisfatórias no ambiente escolar.

Um processo educativo emancipador apoia-se na dialogicidade e no compartilhamento grupal, envolvendo a interdependência de aspectos cognitivos, afetivos e relacionais. Conforme Dourado (2009), existe uma busca por explicitar e delimitar os indicadores da qualidade da educação e da escola, assim essa preocupação se faz presente nos discursos dos governos, movimentos sociais, pais, estudantes e pesquisadores do campo da educação. Nesse sentido,

[...] a educação se articula a diferentes dimensões e espaços da vida social sendo, ela própria, elemento constitutivo e constituinte das relações sociais mais amplas. A educação, portanto, é perpassada pelos limites e possibilidades da dinâmica pedagógica, econômica, social, cultural e política de uma dada sociedade (DOURADO, 2009, p. 202).

A relações sociais representariam, assim, o resultado macro das relações que o indivíduo estabelece com os contextos e das relações que for capaz de estabelecer consigo e com os outros nas interações em pares e em grupos. Saviani, Cascino e Costa (2000, p. 32) indicam que as:

[...] diretrizes da educação no Brasil propõem o estudo publicado pela UNESCO, no relatório de Jacques Dellors, o qual defende a ideia de que educar é desenvolver, no ser humano, quatro competências básicas: pessoal (aprender a ser), relacional (aprender a conviver), produtiva (aprender a fazer) e cognitiva (aprender a conhecer).

Desse modo, apesar de reconhecermos a importância do "aprender a conviver" como ponto primordial para a qualidade da educação e ampliação da aprendizagem, essas questões não são efetivamente contempladas no campo educacional. Constatamos que a realidade do cotidiano escolar, ancorada em uma racionalidade técnica, impõe aspectos mercadológicos, consumista se utilitários ao currículo e às práticas educativas.

Conforme Silva (2008), é necessário romper com algumas características do campo educacional, estabelecidas na modernidade, que estão fortemente ancoradas no estímulo à competitividade e ao centramento no individualismo. Tais características poderiam levar à desvalorização dos encontros dos grupos humanos e obscurecer o papel das interações para a formação dos seres.

Para Moscovici (2012), o movimento de perceber o outro e a si em interação e integração constantesé estimulado a partir das vivências realizadas em grupo. Nesse contexto, Pierre Weil (2002 p. 13) destaca em relação aos processos grupais que, "[...] a intenção é a de desenvolver relações humanas que atinjam o nível das atitudes e de condutas individuais, e não apenas o das opiniões". Esse processo permitiria o crescimento pessoal e grupal.

Em pesquisa desenvolvida pela UNESCO, Casassus (2009, p.157) mostrou que o ambiente socioemocional da escola é uma das esferas centrais na melhoria dos processos de aprendizagem. Para tanto, situou três aspectos: 
[...] 1) que estas são esferas de intervenção e, por isso, podem ser objeto de políticas e medidas públicas; 2) que estas esferas são as que mostraram ter maior impacto no desempenho dos alunos; e, 3) que as intervenções devem se situar no nível das interações. Compreender melhor sua dinâmica é abrir oportunidades para as crianças em situações de desvantagem.

Por sua vez, Delors (2010) ressalta que a história humana sempre foi escrita por conflitos de diferentes ordens, desde os raciais até religiosos. Nesse caso, caberia à educação contribuir no processo de mudança de tal cenário, ampliando seus horizontes em duas vias complementares. A primeira diz respeito à descoberta progressiva do outro sob os seus diferentes e múltiplos aspectos. Já a segunda, inclui uma visão de educação que se estende ao longo de toda a vida, havendo, para isso, a necessidade de participação em projetos que visam ao bem comum.

Assim, o aprender a viver juntos desenvolvendo a compreensão do outro e a percepção das interdependências implica, além de realizar projetos comuns e se preparar para gerir conflitos, na necessidade do respeito pelos valores do pluralismo, da compreensão mútua e da paz (DELORS, 2010). Tais reflexões nos incitam a questionar: até que ponto podemos mapear os deslocamentos grupais de adolescentes que participaram de uma experiência educativa que visava promover a melhoria de relações interpessoais?

A fim de responder tal indagação, realizamos esta pesquisa, cujo objetivo foi apresentar os deslocamentos grupais vivenciados por quatorze adolescentes participantes de uma experiência educativa que buscava promover o desenvolvimento de relações interpessoais. Mais especificamente, indicamos por meio do sociograma o lugar e o status que cada adolescente ocupa dentro do grupo; os líderes e as estruturas de liderança presentes no grupo; a estrutura do grupo e as configurações de subgrupos, isolados, periféricos e solitários que se formam na sua constelação e situamos as justificativas de suas escolhas. Além disso, mapeamos o índice de congruência grupal dos participantes.

\section{Processos grupais no Campo educacional}

Durante toda a existência da humanidade, os processos interativos interpessoais se fizeram presentes. A vida em grupo marcou os diversos modos de aprendizagens, mesmo antes de vivermos organizados na forma de sociedade complexa. O surgimento da educação escolar amplia a necessidade de pensarmos caminhos de promoção das interações saudáveis. As atividades em grupo no campo educacional têm a intenção de favorecera integração, a interação, a aprendizagem de viver juntos entre outras possibilidades. Assim, os processos grupais representam fonte significativa de construção do conhecimento e de crescimento humano. Sabemos também que os processos grupais podem ocorrer a todo o momento, visto que estamos inseridos todo o tempo em grupos pequenos, como os formados pela família ou os grandes grupos como a escola.

Conforme Mailhiot (2013), os processos de aprendizagem ocorrem no contexto de um campo grupal que é, por sua vez, articulado a um campo social. Rosin-Pinola, Martu- 
rano, Elias e Del Prette (2017), Rosin-Pinola e Del Prette (2014) e Del Prette e Del Prette (2008b) apontam que as habilidades sociais são fundamentais para ampliar os processos de aprendizagem e favorecer os processos de formação de normas, comunicação, cooperação e competição, divisão de tarefas e distribuição de poder-liderança. Esses processos estão relacionados à aprendizagem no e pelo grupo.

A Lei de Diretrizes e Bases - LDB 9.394/96, da educação nacional, no artigo 1 apresenta a premissa para a educação e seu "lócus" de desenvolvimento:

A educação abrange os processos formativos que se desenvolvem na vida familiar, na convivência humana, no trabalho, nas instituições de ensino e pesquisa, nos movimentos sociais e nas manifestações culturais (BRASIL, 1998, p.s/p).

De acordo com Barros (2004), a estratégia de organização de pequenos grupos em sala de aula é considerada por diversos pesquisadores em ensino. A explicação para esse fato estaria no reconhecimento de que o trabalho em grupo é capaz de tornar mais frequentes e profundos os insights e as soluções, que não ocorreriam facilmente em processos individuais. Nesse sentido, Bittencourt, Lima e Gessser (2017) indicam o processo grupal como fundamental na promoção de cooperação e manejo das queixas no espaço educacional.

Os grupos em processos educativos são criados de modo institucionalizado e possibilitam, a partir de uma rede de relações intersubjetivas, a formação em experiência e em cooperação. De acordo com Silva (2008, p.89):

O elemento comum a Piaget, Dewey e Lewin, a par, é claro, do foco dado à expe-
rimentação no campo da educação e na relação dialética entre o experimentar e a
reflexão sobre a experiência, reside na presunção de que o aprender é não apenas
um processo, mas, um processo de natureza contínua e que a evolução desse
processo dá-se pela experiência direcionada, polarizada em um objetivo definido.

Para Bastos (2010), a aprendizagem centrada nos processos grupais coloca em evidência a possibilidade de uma nova elaboração e/ou uma reelaboração de conhecimento, integração e questionamentos acerca de si e dos outros. Ela, a aprendizagem, é um processo contínuo em que comunicação e interação são indissociáveis. Aprendemos a partir da relação com os outros. Nesse sentido, criar condições para ampliar a comunicação efetiva e a abertura ao diálogo, em salas de aula, pode gerar situações propícias para aprendizagens significativas e aprendizagem da autenticidade nas relações interpessoais (MAILHIOT, 2013).

Assim, quando decidimos buscar uma reflexão sobre os grupos e as dinâmicas que emergem das interações, pensamos nos grupos em processos formativos. Tais processos, encontrados nos cursos organizados por turmas, nas salas de aula em convivência e nos relacionamentos de aprendizagem, ajudam a compreender as relações interpessoais e suas implicações para aprender a ser e a conviver.

O espaço grupal permite a (re)construção ativa de novas possibilidades de ser e aprender, podendo expandir ou bloquear os processos de crescimento afetivos, cognitivos e relacionais dos participantes (AFONSO; SILVA; ABADE, 2009). O grupo é o lugar privi- 
legiado na construção dos papéis e estes são marcados por características específicas de determinada cultura. Assim, os papéis, como líder, isolado, periférico, precisam ser problematizados, no intuito de promover uma ampliação das relações interpessoais no espaço educacional (MORENO, 1991).

O grupo é um espaço de abertura tecido por uma rede de vínculos entre os participantes. Na medida em que são construídas as relações de cooperação, não impedindo os conflitos, mas minimizando-os, o ambiente de aprendizagem se torna mais acolhedor e o educando encontra forças para se entregar ao "risco" de se educar. O sentimento de acolhimento representa assim um suporte para o processo de aprender (AFONSO; SILVA; ABADE, 2009).

\begin{abstract}
O uso de processos que valorizam a dinâmica de grupo em salas de aula constitui-se em uma possibilidade de exercitar a vivência em ludicidade e em desafio e que, se esta vivência for trabalhada com calço em um plano de ensino estruturado adequadamente, permitirá que os alunos sejam induzidos a reflexões que podem produzir cognição do modus operandi de um dado paradigma, seja esse paradigma qual for, permitindo, por isso mesmo, que o docente possa fazer uso dessa reflexão crítica produzida pelo exercício da dinâmica para extrapolar para diferentes terrenos de sua prática pedagógica, produzindo conhecimento de natureza formativa autóctone (SILVA, 2008, p. 86-87).
\end{abstract}

Um dos destaques no Brasil nos estudos sobre os processos de grupos surge das pesquisas em psicologia social realizados por Moscovici (2012). A autora desenvolveu pesquisas e atividades com o "Laboratório de Sensibilidade", tornando-se uma referência no formato de trabalho com interações grupais. Del Prette e Del Prette (2008) são outras referências para entendermos as relações interpessoais no âmbito educacional.

\title{
O SOCIOGRAMA
}

O sociograma foi proposto por Moreno (1974), como instrumento metodológico para estudar, medir e compreender a rede de relações que se estabelece naturalmente nos grupos. Em última instância, esse instrumento indica a saúde e a patologia das relações humanas em geral e o nível de coesão e da saúde grupal. De acordo com Moreno (1974, p. 41-42), ele é:

[...] um método de pesquisa de estruturas sociais através da medida das atrações e rejeições que existem entre os membros de um grupo. No domínio das relações interpessoais, são utilizados conceitos de significado humano, como 'escolha' e 'aversão' [...].

Bustos (1979) indica que o sociogramafavorece os processos de investigação das relações interpessoais,ocupando-se com o social e a dinâmica dos grupos. Nesse sentido Moreno (1994a, p. 157) aponta que: 
A avaliação de relações interpessoais, bem como, a produção experimental de interação social nunca foram tratados com seriedade. O que resta a ser investigado em uma sociedade, se os próprios indivíduos que a compõem e seus relacionamentos forem considerados de modo fragmentado ou por atacado? Para expressar isto de modo mais positivo, os próprios indivíduos e sua inter-relações devem ser tratados como estrutura nuclear de toda situação social.

Essa avaliação das relações interpessoais pode ser feita pela sociometria, tendo-se o cuidado de evitar a tendência de centrar-se apenas no "metrum". Tal postura foi sinalizada por Moreno (1994a, p.157) no início do desenvolvimento desse método.

Minha primeira definição de sociometria veio, coerente com sua etimologia, do
latim e do grego, mas não enfatizamos apenas a segunda parte do termo, por
exemplo, o 'metrum', significando medida. Também enfatizamos a primeira
parte, ou seja, o 'socius', significando companheiro.

Por meio do sociograma, podemos fazer uso das "[...] representações gráficas das relações existentes em um grupo de indivíduos [...]" (VAZ, 2010, p.67). Reforçando essa visão, Paixão, Muchon e Solomon (2002, p. 166), partindo do trabalho de Moreno, apontam que o teste sociométrico permite "[...] observar, descrever e medir o grau de coesão grupal, ou seja, a rede de relações entre os participantes. [...] pesquisa ele as alterações e as repulsões dos componentes do grupo". Corroborando essa ideia, Naffah Neto (1979) afirma que o objetivo do teste sociométrico é pesquisar a estrutura dos grupos humanos, suas configurações fixas e móveis, suas formações e transformações e toda a força criadora que os anima em seus movimentos espontâneos de abertura, participação e comprometimento com sua própria existência intersubjetiva.

Gil (1995, p. 154) indica que sua aplicação no campo educacional possibilita:

[...] a obtenção, com bastante precisão, dos seguintes dados: a) a posição que cada um dos componentes ocupa no grupo, bem como, a que julga ocupar; b) as relações de afinidade e de conflito entre os componentes do grupo; c) a estrutura sociométrica do grupo; rede de comunicações, focos de tensões, subgrupos etc.; d) a dinâmica dos grupos: modificações dos quadros e evolução dos processos grupais.

Estudos recentes utilizando a sociometria ampliam essa discussão em diferentes perspectivas. Destacamos o uso de sociogramas na escola para a melhoria da convivência (HURTADO; LEIVA; CÁRDENAS-VILLALOBOS, 2018);a relação do status sociométrico e a avaliação das interações sociais em crianças do ensino fundamental 1 (NUNES, 2017); o uso de técnicas sociométricas para avaliação do impacto social de inclusão (AVRAMIDIS;STROGILOS; ARONI; KANTARAKI, 2017); e a relação sociometria e habilidades sociais em alunos do ensino médio (BARTHOLOMEU; MONTIEL; PESSOTTO, 2011).

No sociograma moreniano, os conceitos de "Tele" e "Transferência" são fundamentais para entendermos a dinâmica presente nos grupos. Esses conceitos nos ajudam a compre- 
ender os múltiplos papéis vividos por um indivíduo dentro do grupo, assim como, podem nos oferecer pistas sobre os significados de amizade, encontro, diálogo e da extrema complexidade da rede de relações, com seus movimentos de atração, repulsão e de indiferença.

Buscando encontrar uma alternativa baseada na saúde para explicar as relações e romper com a visão patológica que apoiava o conceito de transferência, estabelecido pela psicanálise, Moreno (1974) propõe o conceito de "Tele". Ele o apresenta como o conjunto de percepções, ideias e sentimentos que o homem desenvolve progressivamente, desde o nascimento, em relação às pessoas e aos objetos que o cercam no interior do seu sistema social e que determinam a natureza, a direção e a intensidade das relações interpessoais.

A "Tele" é considerada um dos fundamentos básicos de todas as relações interpessoais saudáveis e o elemento essencial de todo método eficaz de formação humana. Ela repousa na percepção, no sentimento e no conhecimento da situação real que o indivíduo desenvolve em relação às outras pessoas. Isso pode surgir ocasionalmente de uma situação de transferência infantil, mas se desenvolve como estrutura independente desta. Ela sempre existe, desde os primeiros encontros, na origem da vida social, e cresce de um encontro para outro, podendo, por vezes, ser deformada pela influência de fantasias transferenciais (MORENO, 1974).

Nesse sentido, complementa Bustos (1979, p. 17),

\begin{abstract}
Tele implica um conceito existencial e totalizador, intelectivo, afetivo, biológico e social. Ao abandonar o acaso em nossa infância, começa a seleção. Buscamos sociometricamente aqueles que complementem positivamente nossos objetivos, rechaçamos outros ou permanecemos indiferentes a terceiros. Quando se dá o encontro, existe a certeza de que não são necessárias verbalizações de confirmação. Produzem-se respostas-condutas coerentes com as propostas. Deste modo, sabemos que é o fator tele que está funcionando. $\mathrm{O}$ vínculo adquire as características que nascem da complementação, mas para o conhecimento desta dinâmica é necessário avaliar a intensidade da eleição.
\end{abstract}

A “Tele", portanto, está associada à saúde da relação, enquanto a transferência é a sua distorção patológica. Na relação télica, o indivíduo sente e percebe o outro de forma realista, tal como ele é, e se aproxima ou se distancia dele motivado por esse conjunto de sentimentos e percepções que decorrem da relação.

Na relação transferencial, ao contrário, o outro é percebido de forma distorcida, a partir de seus "fantasmas" internos. Os últimos são os motivadores de suas percepções e seus sentimentos e das consequentes aproximações e distanciamentos.

\title{
Metodologia
}

Esta pesquisa, de forma mais ampla, situa-se no campo multiparadigmático da pesquisa mista (CRESWELL, 2010). Dada a complexidade do fenômeno investigado, montamos uma estratégia de buscar compreendê-lo por diversos ângulos a partir de uma série de atividades que visavam apreender os deslocamentos grupais vivenciados pelos participantes 
de uma experiência educativa. Foram investigados 14 adolescentes de baixa renda, com faixa etária entre 14 e 17 anos, frequentando do $6^{\circ}$. ano do ensino fundamental ao $2^{\circ}$. ano do ensino médio quando da conclusão da pesquisa. Eles foram identificados com nomes fictícios para preservar suas identidades. Os participantes estudavam pela manhã em escolas de ensino formal (públicas) da cidade do Recife e no período da tarde faziam parte de um curso de educação não formal, oferecido por uma entidade de caráter civil da comunidade do Coque, Recife, e que tinha por objetivo favorecer processos grupais.

A construção dos dados deu-se por meio do Teste Sociométrico seguindo as etapas sugeridas por Moreno (1992): definição dos critérios sociométricos; coleta dos dados aplicação do teste sociométrico ao grupo que está sendo analisado; cruzamento de dados - a fim de encontrar as relações existentes entre os indivíduos; construção do sociograma - visualização de dados; análise e interpretação dos dados da pesquisa; intervenção junto ao grupo. Acrescentamos uma avaliação posterior à intervenção.

Inicialmente, definiu-se o critério sociométrico (BUSTOS, 1997), ou seja, propomos três questões para avaliar a situação afetiva, a situação intelectual e cultural e a situação funcional. A seguir, passamos para a etapa de coleta dos dados, na qual o pesquisador entregou a cada um dos participantes uma Ficha de Sociograma, adaptada do questionário "Quem escolhe quem" desenvolvido por Paixão; Muchon e Solomon (2002), contendo três perguntas, relacionadas às situações: situação afetiva (Quem eu escolheria para meu companheiro de diversões), situação intelectual e cultural (A quem do grupo eu escolheria para me ajudar nos estudos) e situação funcional (A quem eu escolheria para ser meu representante de turma). O critério de escolha dessas três situações foi montado com os membros do grupo que deveriam escolher uma situação plausível de ser realizada.

Cada um dos participantes foi estimulado a escolher três companheiros para cada uma das atividades, sem se preocupar com as respostas apresentadas. Após os participantes terem realizado suas escolhas, e em acréscimo às etapas morenianas, pedimos para justificá-las, pois tínhamos interesse em compreender suas motivações. A partir das escolhas feitas pelos participantes, montamos uma sociomatriz de todas as escolhas realizadas. Na parte final desse quadro sociomatriz tínhamos o somatório dos votos recebidos pelo indivíduo dividida por primeira escolha, segunda escolha, terceira escolha e total de votos.

Com as respostas dadas pelos membros do grupo e registradas na Sociomatriz de Escolhas, montamos manualmente os sociogramas (BUSTOS, 1997, MORENO, 1992) que, por sua vez, serviu de base para a análise e compreensão das relações intersubjetivas que ocorrem no grupo. Os sociogramas montados foram analisados a partir das sugestões de Moreno (1992) e Bustos (1997). Neste estudo, realizamos uma breve análise temática (2010) dos motivos das escolhas.

A partir da identificação da rede de relações da turma, montaram-se intervenções com vistas ao desenvolvimento grupal. As intervenções organizaram-se a partir da realização de 30 encontros e seguiam os moldes dos grupos de sensibilidade de Moscovici $(2004,2012)$. Os encontros foram realizados numa sala de aula de uma organização da sociedade civil. Cada encontro de intervenção seguia três momentos vivenciais espiralados: 
$1^{\circ}$. Momento: INTROSPECÇÃO - EU COMIGO MESMO - Cada participante era orientado num clima de tranquilidade e silêncio a refletir e a tentar se perceber, entrar em contato consigo mesmo, observar suas emoções e seu estado de espírito ou a realizar atividades direcionadas com essa intenção. A intenção era propor uma espécie de preparação para as interações com o grupo.

$2^{\circ}$. Momento: DIALÓGICO "EU COM OS OUTROS" - Abertura de roda de diálogos para socializar as reflexões feitas individualmente, seguida de dinâmicas grupais apresentadas por Moscovici $(2012,2004)$.

$3^{\circ}$. Momento: CONVIVER - NÓS TODOS - Todos juntos foram envolvidos em atividades de tarefa, um momento de criação. Assim, várias oportunidades foram propostas: elaboração de cartazes, cenas teatrais ou qualquer expressão simbólica, que representem o que foi compreendido/aprendido no dia sobre a temática. Ao final de cada encontro os estudantes eram convidados a registrar de forma verbal ou escrita quais os sentimentos e impressões do encontro vivenciado.

Durante todos os encontros, realizamos a observação participante na perspectiva de Malheiros (2011). Com a observação participante, podemos aprofundar a análise das categorias surgidas pelo estudo dos sociogramas obtidos.

Para além da intervenção, incluímos um pré-encontro, no qual apresentamos o Termo de Consentimento Livre e Esclarecido (TCLE) e aplicamos o Teste Sociométrico Inicial. Também acrescentamos um encontro final, que ocorreu 28 dias depois que encerramos as intervenções no grupo, no qual reaplicamos o Teste Sociométrico Final no intuito de acompanhar se houve deslocamentos dos participantes dentro da estrutura grupal. Após o término da reaplicação do teste sociométrico, apresentamos os sociogramas do primeiro momento e uma visão parcial do sociograma final aos participantes e educadores, gerando um momento de reflexão acerca do que eles percebiam que havia mudado e o que necessitaria ser revisitado nas relações do grupo.

Mantiveram-se os mesmos formulários e instruções nesses dois momentos, assim como os participantes só tiveram contato com os gráficos dos sociogramas após a realização do teste final. Havia um acordo com os participantes que após o termino da pesquisa manteríamos o trabalho grupal.

\section{Resultados}

Apresentamos a seguir quatro sociogramas que, de uma forma mais direta, revelam os principais aspectos da rede de relações que se forma a partir do critério utilizado nas respostas ao Teste Sociométrico, bem como, as relações de lideranças que se estabelecem na estrutura do grupo.

O primeiro Sociograma (Figura 1) nos mostra, como uma espécie de fotografia panorâmica do grupo no início e ao final da observação, o conjunto de todas as eleições (positivas) decorrentes do Teste Sociométrico. Ele indica a natureza, as congruências das eleições

146 Comunicações | Piracicaba | v. 25 | n. 2 | p. 137-166| maio-ago. 2018 
e as direções das atrações que se estabelecem no grupo em função do critério estabelecido para as três situações escolhidas nesta pesquisa: situação afetiva, situação intelectual e situação funcional.

A ordem e a direção das eleições são representadas por setas em cores diferentes. As setas na cor vermelha indicam as eleições na situação afetiva, as azuis indicam as eleições na situação intelectual e as verdes indicam as eleições na situação funcional.

Figura 1: Sociograma geral das três situações pesquisadas
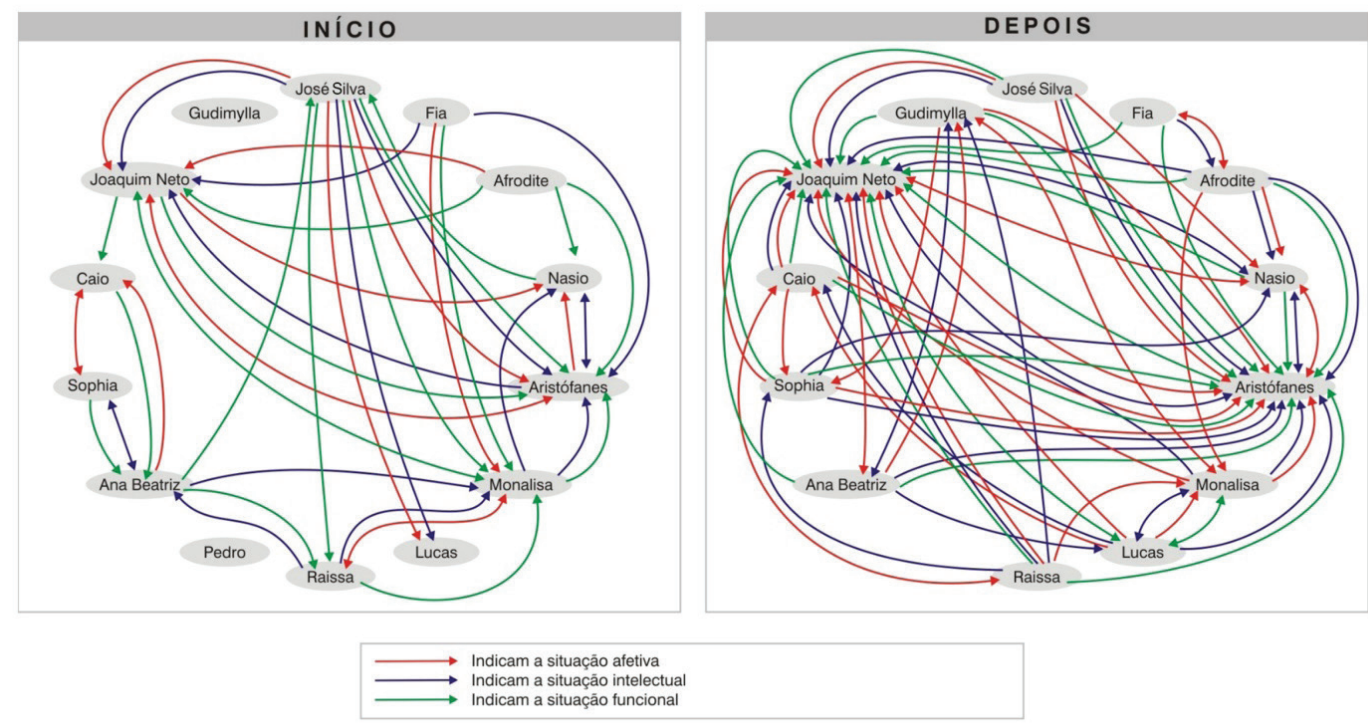

Fonte: Os autores.

No Sociograma citado, todos os aspectos da rede sociométrica do grupo são representados graficamente da seguinte forma:

a) A natureza das eleições - as eleições positivas (atrações) no grupo são marcadas por setas, sendo as setas vermelhas indicadoras da situação afetiva, enquanto as setas azuis indicam a situação intelectual e as setas verdes a situação funcional.

b) A direção das eleições - a origem e a direção das setas indicam aquele que realiza as eleições e a quem elas se dirigem.

c) As congruências das eleições (mutualidades) - quando duas pessoas do grupo se elegem mutuamente de forma positiva (escolhem-se mutuamente), haverá setas com pontas duplas, indicando a mutualidade das escolhas.

Utilizamos, ainda, a nomenclatura moreniana para expressar as diferentes posições dos indivíduos no grupo:

1. Subgrupo - indica o número de subgrupos existentes dentro do grupo;

2. Solitário - o que não escolhe e que também não é escolhido pelos outros participantes. 
3. Periférico - indivíduo que escolhe, mas que não é escolhido por ninguém;

4. Líder - indivíduo mais votado ou aquele que recebeu maior número de escolhas;

5. Isolado - é escolhido, mas não escolhe alguém.

Assim, diante do Sociograma em questão, podemos observar, não obstante o congestionamento visual, que, de todas as eleições positivas feitas pelos membros do grupo, formam-se as tabelas T1, T2, T3, T4 e T5. Essas tabelas indicam, respectivamente, o número de subgrupos, participantes solitários, periféricos, concentração em torno do líder e isolados. Esses dados prestam-se para observar as mudanças na estrutura do grupo acompanhado.

Tabela 1: Número de subgrupos nas três situações estudadas.

\begin{tabular}{ccc}
\hline Situações & \multicolumn{2}{c}{ Subgrupos } \\
\cline { 2 - 3 } & Início & Final \\
\hline Situação Afetiva & 5 & 0 \\
\hline Situação Intelectual & 5 & 0 \\
\hline Situação Funcional & 4 & 0 \\
\hline Total & 14 & 0 \\
\hline
\end{tabular}

Fonte: Os autores.

Uma visão geral dessa tabela nos permite perceber uma ausência de subgrupos ao final da avaliação, o que indica a presença de um aumento na rede de relações grupais. Isso parece revelar, em função da ausência de subgrupos, que o grupo de alunos teve uma evolução na estrutura das relações grupais a partir da experiência vivenciada, pois a presença de subgrupos demonstra que o grupo ainda está na fase de agrupamento, não havendo ainda uma estrutura de grupo na rede de relações. Não foram encontradas diferenças entre as três situações pesquisadas (afetiva, intelectual e funcional) quanto ao número de subgrupos.

Tabela 2: Número de Solitários nas três situações estudadas.

\begin{tabular}{ccc}
\hline Situações & \multicolumn{2}{c}{ Solitários } \\
\cline { 2 - 3 } & Início & Final \\
\hline Situação Afetiva & 2 & 0 \\
\hline Situação Intelectual & 4 & 0 \\
\hline Situação Funcional & 3 & 0 \\
\hline
\end{tabular}

Fonte: Os autores.

Como destaca a teoria moreniana, o solitário é alguém que ainda não faz parte do grupo, pois não se sente vinculado a alguém, como também não é incluído pelos outros participantes. No grupo em estudo, tivemos no início a presença de cinco solitários no total das 
situações, sendo que a situação intelectual era a que favorecia o maior aparecimento desse fenômeno, quatro alunos ao todo. Desses quatro alunos, dois (Gudimylla e Pedro) não se ligavam ao grupo em qualquer das três situações, o que nos leva a pensar nas dificuldades apresentadas, principalmente por Pedro, para permanecer no grupo, já que Gudimylla ao final estava incluída na rede de relações, enquanto ele não foi nem citado na composição da rede grupal. Vale salientar que esse aluno apresentava desde o início da intervenção uma extrema dificuldade de acompanhar as atividades do grupo, tanto cognitivo, como afetivo e relacional, permanecendo no curso pela "[...] insistência da mãe, que queria porque queria que o filho conseguisse melhorar de vida" (Observação participante).

Ao final da avaliação, todos os indivíduos estavam incluídos no grupo, com exceção de Pedro, que saiu do grupo antes da sua conclusão. Isso pode indicar que houve um aumento dos processos de inclusão dentro do grupo, pois esses alunos passaram a fazer parte da teia grupal.

Tabela 3: Número de Periféricos nas três situações estudadas.

\begin{tabular}{ccc}
\hline Situações & \multicolumn{2}{c}{ Periféricos } \\
\cline { 2 - 3 } & Início & Final \\
\hline Situação Afetiva & 4 & 2 \\
\hline Situação Intelectual & 3 & 4 \\
\hline Situação Funcional & 3 & 10 \\
\hline
\end{tabular}

Fonte: Os autores.

Os periféricos são os elementos que ocupam as margens do grupo e tenderam a aumentar de número com o processo de intensificação das relações grupais, da redução dos subgrupos e forte concentração em torno de alguns líderes.O aumento dos periféricos também indica uma intensa movimentação interna na rede grupal, na qual os seus elementos estão em um processo de movimento dinâmico em busca de novas parcerias que lhes permitam uma participação mais efetiva dentro do grupo. Assim, se espera uma diminuição gradativa do número de periféricos ao longo do trabalho; contudo, na etapa de reorganização grupal era esperado esse aumento.

Tabela 4: Número de Concentração máxima em torno do "líder" nas três situações estudadas

\begin{tabular}{ccc}
\hline & \multicolumn{2}{c}{ Concentração máxima em torno do Líder } \\
\cline { 2 - 3 } & Início & Final \\
\hline Situação Afetiva & 3 & 9 \\
\hline Situação Intelectual & 4 & 8 \\
\hline Situação Funcional & 4 & 11 \\
\hline
\end{tabular}

Fonte: Os autores. 
Segundo Moreno (1992), o termo "líder" se refere à pessoa no grupo que recebe mais do que o número esperado de escolhas. O líder é aquela pessoa que assume a tarefa de orientar e influenciar os membros do grupo na direção de suas metas.

O índice de eleições positivas recebidas por determinado membro do grupo indica o grau de liderança que ele exerce na estrutura grupal. Nesse sentido, podemos perceber que após a experiência houve um aumento significativo tanto no número de lideranças potenciais, como a emergência de fortes lideranças. Os alunos Joaquim Neto e Aristófanes, que já sinalizavam um potencial de liderança no início do trabalho, se fortaleceram, conseguindo atrair um maior número de participantes.

A compreensão do fenômeno liderança supõe entendermos as redes de relações que se estabelecem entre os membros de determinado grupo em um contextoespecífico. Como afirma Moreno (1994b, p. 198),

\footnotetext{
Liderar é função da estrutura grupal. A forma que assume depende da constelação do grupo em particular. O índice de poder de determinado líder depende dos índices de poder das pessoas que são atraídas e influenciadas por ele. Tais índices são expressos, da mesma forma, pelo número de pessoas atraídas e dominadas por elas. Portanto, o índice de força do líder também depende das redes de comunicação psicossocial a que estas pessoas pertencem e da posição que as próprias redes têm em toda a coletividade onde sua liderança opera.
}

Nesse sentido, houve um incremento da liderança no nível funcional, possivelmente decorrente do fato de terem sido as duas lideranças mais votadas, nessa área, responsáveis por dirigirem o grupo de discussão dos alunos. Esse grupo foi criado pelos alunos para favorecer o fortalecimento dos laços entre eles e também ajudar nos processos de negociação com a instituição. Não houve diferença na escolha entre as lideranças nas três situações, ou seja, os líderes escolhidos estavam presentes nas situações afetiva, intelectual e funcional. Isso nos parece apontar que a escolha do líder estava sendo feita mediante a sua capacidade de congregar coerentemente as várias dimensões pesquisadas.

O termo "liderança", aqui utilizado, se refere ao modo pelo qual a pessoa, na posição de líder, orienta e influencia os demais membros do grupo. Daí podermos falar em "estilos de liderança" (BERGAMINI, 1994). Nesse sentido, mais que o aumento da liderança, buscamos pela observação participante também perceber qual o estilo das lideranças escolhidas pelo grupo. No início do curso, por exemplo, o aluno Aristófanes era escolhido como líder pelo seu potencial cognitivo; contudo, permanecia isolado, negando-se a estabelecer contato e a assumir tal posição. Assim, concluímos que as lideranças eram escolhidas no final por sua capacidade de estabelecer um relacionamento intra e interpessoal sob todos os aspectos, seja na relação com os seus pares, seja na relação com as instâncias superiores ou externas ao grupo. 
Tabela 5: Número de Isolados para as três situações estudadas.

\begin{tabular}{ccc}
\hline & \multicolumn{2}{c}{ Isolados } \\
\cline { 2 - 3 } & Início & Final \\
\hline Situação Afetiva & 2 & 0 \\
\hline Situação Intelectual & 2 & 0 \\
\hline Situação Funcional & 1 & 0 \\
\hline
\end{tabular}

Fonte: Os autores.

O número de isolados, ou seja, o número de alunos que são eleitos, mas não escolhem alguém foi nulo ao final da observação. Isso demonstra que todos os participantes se encontram interligados em uma complexa teia de relações, na qual mesmo que alguém não escolha acaba se vinculando ao grupo pela força de atração das eleições sobre si.

\section{ÍNDICE DE MUDANÇA}

Procuramos também acompanhar as modificações gerais da posição dos alunos no grupo nas três situações pesquisadas, como mostram os sociogramas F2, F3 e F4 a seguir e os quadros com as mudanças ocorridas. Para tal análise, tomamos como parâmetro que cada participante da pesquisa tinha a possibilidade de três escolhas, gerando assim um parâmetro de análise escalonar de 0 a 3.

Figura 2: Situação Afetiva: Quem eu escolheria para meu companheiro de diversões
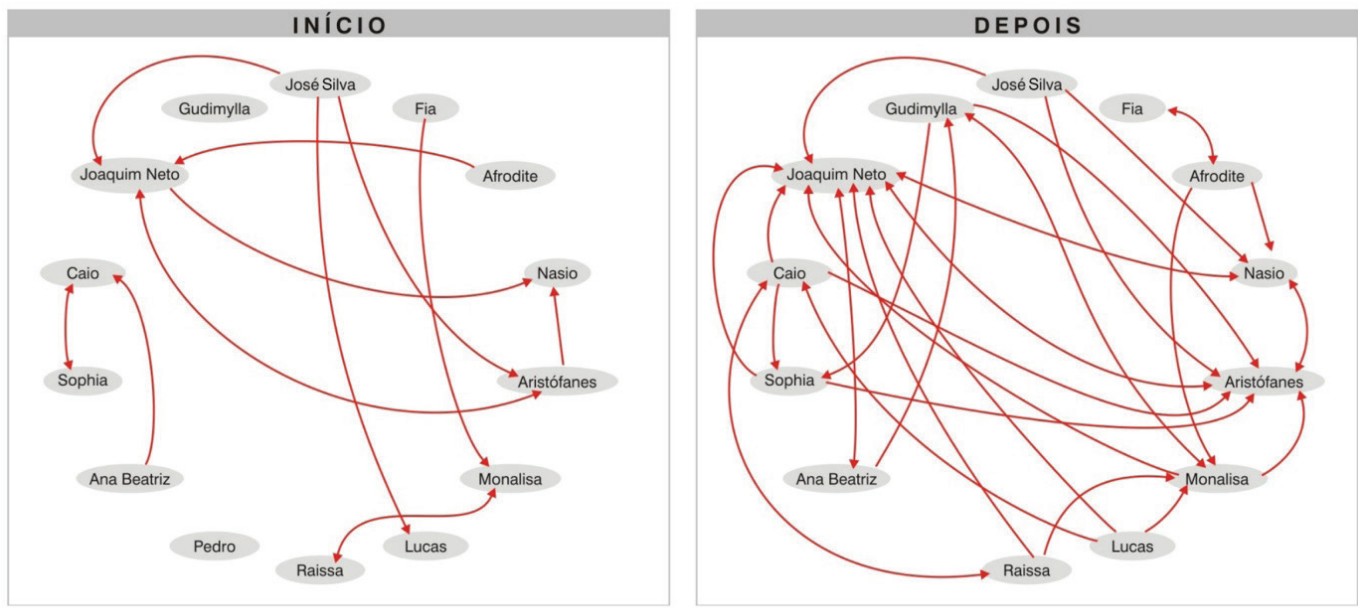

Fonte: Os autores. 
Quadro 1: Índice de mudança da situação afetiva.

\begin{tabular}{|c|c|c|}
\hline \multirow[t]{2}{*}{ Participantes } & \multicolumn{2}{|c|}{$\begin{array}{c}\text { Escolhas dos Participantes } \\
\text { Situação Afetiva: Quem eu escolheria para meu companheiro de diversões }\end{array}$} \\
\hline & Início & \begin{tabular}{|c|} 
Final \\
\end{tabular} \\
\hline José Silva & Aristófanes, Lucas e Joaquim Neto & Nasio, Aristófanes e Joaquim Neto \\
\hline Gudimylla & Não escolhe ninguém & Aristófanes, Sophia \\
\hline Joaquim Neto & Nasio, Aristófanes & Nasio, Aristófanes, Monalisa \\
\hline Caio & Sophia & Sophia, Joaquim Neto, Aristófanes \\
\hline Sophia & Caio & Raissa, Aristófanes, Joaquim \\
\hline Ana Beatriz & Caio & Gudimylla, Joaquim Neto \\
\hline Pedro & Não escolheu ninguém & Os dados não foram computados \\
\hline Raissa & Monalisa & Monalisa, Joaquim Neto, Sophia \\
\hline Lucas & Não escolheu ninguém & Monalisa, Caio, Joaquim Neto \\
\hline Monalisa & Raissa & Aristófanes, Joaquim Neto, Gudimylla \\
\hline Aristófanes & Nasio, Joaquim Neto & Nasio, Joaquim Neto \\
\hline Nasio & Não escolheu ninguém & Aristófanes, Joaquim Neto \\
\hline Afrodite & Joaquim & Fia, Nasio, Monalisa \\
\hline Fia & Monalisa & Monalisa, Afrodite \\
\hline
\end{tabular}

Fonte: Os autores.

Na situação afetiva ocorreram 25 mudanças de posições na escolha individual de cada participante do grupo (vide Quadro 1), acarretando assim um índice de mudança de $76 \%$ em relação ao total das escolhas finais. Constatamos assim que bem mais da metade do grupo apresentou mudanças de posições, após a observação da experiência.

Figura 3: Situação Intelectual: Quem do grupo eu pediria para me ajudar nos estudos
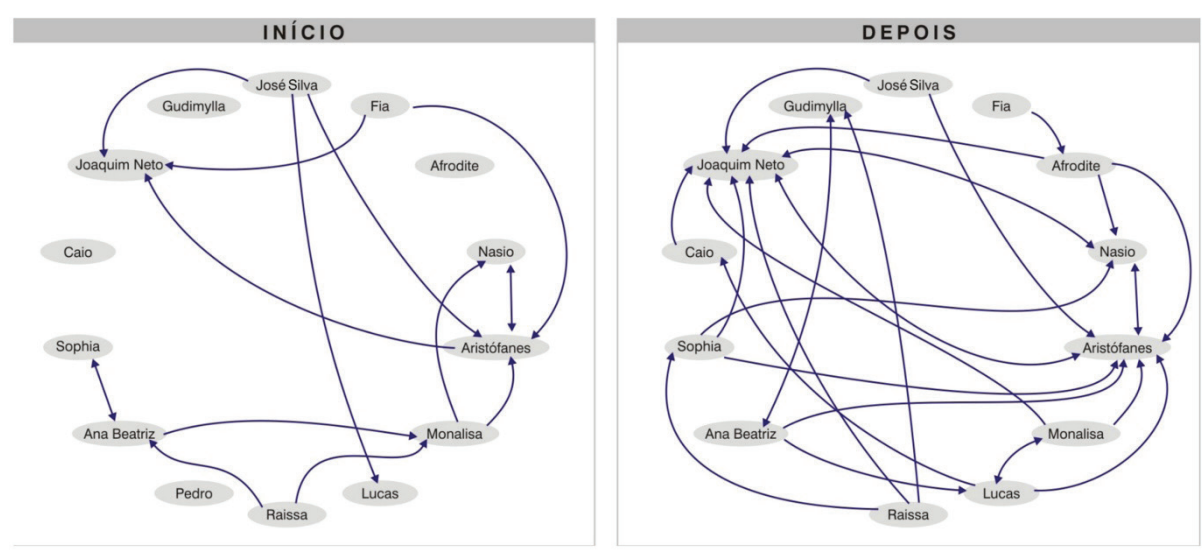

Fonte: Os autores.

152 Comunicações | Piracicaba | v. 25 | n. 2 | p. 137-166 | maio-ago. 2018 
Quadro 2: Índice de mudança da situação intelectual.

\begin{tabular}{|c|c|c|}
\hline \multirow[t]{2}{*}{ Participantes } & \multicolumn{2}{|c|}{$\begin{array}{l}\text { Escolhas dos Participantes } \\
\text { Situação Intelectual: Quem do grupo eu pediria para me ajudar nos estudos }\end{array}$} \\
\hline & Início & Final \\
\hline José Silva & Aristófanes, Lucas, Joaquim Neto & Aristófanes, Joaquim Neto \\
\hline Gudimylla & Não escolhe ninguém & Ana Beatriz \\
\hline Joaquim Neto & Não escolhe ninguém & Aristófanes, Nasio \\
\hline Caio & Não escolhe ninguém & Joaquim Neto \\
\hline Sophia & Ana Beatriz & Joaquim Neto, Nasio, Aristófanes \\
\hline Ana Beatriz & Monalisa, Sophia & Gudimylla, Aristófanes, Lucas \\
\hline Pedro & Não escolhe ninguém & Os dados não foram computados \\
\hline Raissa & Ana Beatriz, Monalisa & Gudimylla, Joaquim Neto, Sophia \\
\hline Lucas & Não escolheu ninguém & Aristófanes, Caio, Monalisa \\
\hline Monalisa & Nasio, Aristófanes & Aristófanes, Lucas, Joaquim Neto \\
\hline Aristófanes & Nasio, Joaquim Neto & Nasio, Joaquim Neto \\
\hline Nasio & Aristófanes & Aristófanes, Joaquim Neto \\
\hline Afrodite & Não escolheu ninguém & Nasio, Aristófanes, Joaquim Neto \\
\hline Fia & Aristófanes & Afrodite \\
\hline
\end{tabular}

Fonte: Os autores.

Na situação intelectual ocorreram 23 mudanças de posições dentro do grupo (vide Quadro 2), indicando que o índice de mudança foi de $79 \%$ em relação ao total das escolhas finais. Ou seja, bem mais da metade do grupo apresentou mudanças de posição após a observação da experiência.

Figura 4: Situação Funcional: A quem eu escolheria para ser meu representante de turma.
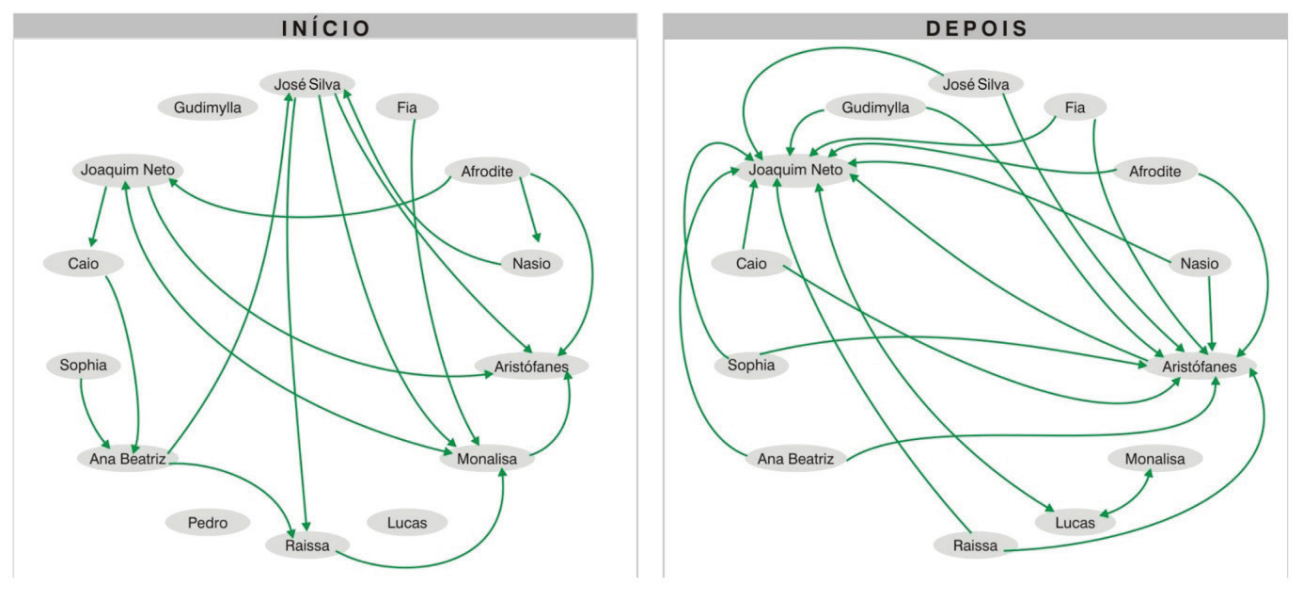

Fonte: Os autores. 
Quadro 3: Índice de mudança da situação funcional.

\begin{tabular}{|c|c|c|}
\hline \multirow[t]{2}{*}{ Participantes } & \multicolumn{2}{|c|}{$\begin{array}{l}\text { Escolhas dos Participantes } \\
\text { Situação Funcional: A quem eu escolheria para ser meu representante de turma }\end{array}$} \\
\hline & Início & $\begin{array}{ll}\text { Final } \\
\end{array}$ \\
\hline José Silva & Aristófanes, Monalisa, Raissa & Aristófanes, Joaquim Neto \\
\hline Gudimylla & Não escolheu ninguém & Aristófanes, Joaquim Neto \\
\hline Joaquim Neto & Aristófanes & Lucas \\
\hline Caio & Ana Beatriz & Joaquim Neto, Aristófanes \\
\hline Sophia & Ana Beatriz & Joaquim Neto, Aristófanes \\
\hline Ana Beatriz & Raissa, José Silva & Joaquim Neto, Aristófanes \\
\hline Pedro & Não escolheu ninguém & Os dados não foram computados \\
\hline Raissa & Monalisa & Joaquim Neto, Aristófanes \\
\hline Lucas & Não escolheu ninguém & Monalisa, Joaquim Neto \\
\hline Monalisa & Joaquim Neto, Aristófanes & Lucas \\
\hline Aristófanes & Não escolheu ninguém & Joaquim Neto \\
\hline Nasio & José Silva & Joaquim Neto, Aristófanes \\
\hline Afrodite & Joaquim Neto, Nasio, Aristófanes & Joaquim Neto \\
\hline Fia & Monalisa & Joaquim Neto, Aristófanes \\
\hline
\end{tabular}

Fonte: Os autores.

Na situação funcional ocorreram 20 mudanças de posições na escolha individual de cada participante do grupo (vide Quadro 3), o que nos dá um índice de mudança de $91 \%$ em relação ao total das escolhas finais. Isso indica que quase todo o grupo mudou de posição ao final da experiência.

Contabilizando as três situações pesquisadas, ocorreram no geral 68 mudanças de posições dentro do grupo, o que nos dá um índice de mudança de $81 \%$ em relação ao total das escolhas finais, ou seja, a grande maioria do grupo mudou de preferência após o trabalho realizado no grupo. Não houve diferença entre as mudanças da situação afetiva e intelectual, o que nos oferece mais uma pista de que as mudanças estavam ocorrendo em função de uma percepção mais integral do outro, não separação entre afeto e cognição. Contudo, houve um grande aumento nas mudanças no que diz respeito à situação funcional, possivelmente pelo aumento e fortalecimento das lideranças e redução no número de subgrupos, pois isso favorecia a agregação dos participantes, inclusive dos que estavam isolados e solitários dentro do grupo.

As mudanças sugerem que os participantes se reconheciam mutuamente, ou seja, os alunos tinham "representações internas" uns dos outros, o que implicava que cada um era percebido e discriminado como um elemento específico e único daquele grupo. Isto é, os membros do grupo deixaram de ser totais estranhos uns para os outros, perdendo a perspectiva de serem "rostos anônimos da multidão". 


\section{Motivos das escolhas}

As escolhas dos participantes eram acompanhadas de justificativa, de forma que a partir de sua análise, conseguimos montar 11 categorias que nos pareceram contemplar a gama de informações oferecidas. Essas categorias, com exemplos extraídos dos protocolos dos participantes, são apresentadas no Quadro 4.

Quadro 4: Categorias de escolhas dos participantes.

\begin{tabular}{|l|l|}
\hline \multicolumn{1}{|c|}{ Categorias } & \multicolumn{1}{|c|}{ Exemplos de discurso na linguagem dos participantes } \\
\hline $\begin{array}{l}\text { 1. Afinidade - Simpatia (afinida- } \\
\text { de afetiva e de pontos de vista). }\end{array}$ & $\begin{array}{l}\text { "amigos, pessoa que eu conhecia, mais próxima"; "amigos, } \\
\text { sentia muito bem"; "única que tinha amizade completa" }\end{array}$ \\
\hline $\begin{array}{l}\text { 2. Conhecimento antes do curso } \\
\text { (convivência antes do curso). }\end{array}$ & $\begin{array}{l}\text { "Tinha já contato antes, intimidade"; "era todos conhecidos } \\
\text { por mim" }\end{array}$ \\
\hline $\begin{array}{l}\text { 3. Status (idade, mesmo nível } \\
\text { escolar) }\end{array}$ & "mesmo nível de escola, assuntos comuns" \\
\hline $\begin{array}{l}\text { 4. Aproximação física (familiar, } \\
\text { vizinhos) }\end{array}$ & $\begin{array}{l}\text { "além de ser minha sobrinha, gostava e odiava as mesmas } \\
\text { coisas que eu" }\end{array}$ \\
\hline $\begin{array}{l}\text { 5. Capacidade, competência, } \\
\text { experiência }\end{array}$ & $\begin{array}{l}\text { "Demonstra saber do assunto, e faz o que fala"; Achava que } \\
\text { era mais inteligente, inteligência não só de cabeça"; "sabe } \\
\text { falar com agente, como conversar sério, trata bem" }\end{array}$ \\
\hline $\begin{array}{l}\text { 6. Era compreensivo, sincero, } \\
\text { mostrava vontade de ajudar }\end{array}$ & "Compreende bem as pessoas e mostra disposição para ajudar" \\
\hline $\begin{array}{l}\text { 7. Reconhecimento (atenção dis- } \\
\text { pensada) }\end{array}$ & "Combinava para fazer a tarefa, dava atenção a pessoa" \\
\hline 8. Ser responsável & "Era responsável, parecia ser responsável” \\
\hline $\begin{array}{l}\text { 9. Sociabilidade (atitude extro- } \\
\text { vertida, boas maneiras - bom } \\
\text { trato) }\end{array}$ & $\begin{array}{l}\text { "Se dá bem com todos", "engraçados, brincalhões", "Eram } \\
\text { divertidos e de bom coração" }\end{array}$ \\
\hline $\begin{array}{l}\text { 10. Era quieto e fazia todas as } \\
\text { atividades }\end{array}$ & "Era quieto e fazia todas as atividades" \\
\hline $\begin{array}{l}\text { 11. Grande avanço na autofor- } \\
\text { mação }\end{array}$ & "Grande avanço na autoformação" \\
\hline
\end{tabular}

Fonte: Os autores.

Partindo desse conjunto de categorias, procuramos analisar as respostas oferecidas pelos alunos que realizaram escolhas nas três situações estudadas: Afetiva (Quem eu escolheria para meu companheiro de diversões), Intelectual (Quem do grupo eu pediria para me ajudar nos estudos) e Funcional (A quem eu escolheria para ser meu representante de turma). Os participantes que não escolheram alguém não foram incluídos nesse quadro. Os motivos da não-escolha serão analisados posteriormente. Voltamos a lembrar que o participante Pedro esteve apenas no início dessa atividade, tendo saído do curso antes de realizar 
a segunda avaliação. Assim, a frequência de participantes nas onze categorias de motivos das escolhas será apresentada no quadro a seguir.

Tabela 6: Frequência dos participantes por motivo das escolhas.

\begin{tabular}{|c|c|c|c|c|c|c|}
\hline \multirow{3}{*}{$\begin{array}{l}\text { Categorias de Motivos das } \\
\text { Escolhas }\end{array}$} & \multicolumn{6}{|c|}{ Freqüencia de Participantes } \\
\hline & \multicolumn{2}{|c|}{$\begin{array}{l}\text { Quem eu es- } \\
\text { colheria para } \\
\text { meu compa- } \\
\text { nheiro de di- } \\
\text { versões }\end{array}$} & \multicolumn{2}{|c|}{$\begin{array}{l}\text { Quem do grupo eu } \\
\text { escolheria para me } \\
\text { ajudar nos estudos }\end{array}$} & \multicolumn{2}{|c|}{$\begin{array}{l}\text { A quem eu esco- } \\
\text { lheria para ser } \\
\text { meu representante } \\
\text { de turma }\end{array}$} \\
\hline & Início & Final & Início & Final & Início & Final \\
\hline $\begin{array}{l}\text { 1. Afinidade - Simpatia (afinida- } \\
\text { de afetiva e de pontos de vista). }\end{array}$ & 5 & 2 & 2 & 0 & 2 & 0 \\
\hline $\begin{array}{l}\text { 2. Conhecimento antes do curso } \\
\text { (convivência antes do curso). }\end{array}$ & 4 & 0 & 1 & 0 & 0 & 0 \\
\hline $\begin{array}{l}\text { 3. Status (idade, mesmo nível } \\
\text { escolar) }\end{array}$ & 0 & 0 & 1 & 1 & 0 & 0 \\
\hline $\begin{array}{l}\text { 4. Aproximação física (familiar, } \\
\text { vizinhos) }\end{array}$ & 1 & 0 & 0 & 0 & 0 & 0 \\
\hline 5. Competência, experiência & 0 & 3 & 2 & 7 & 1 & 11 \\
\hline $\begin{array}{l}\text { 6. Era compreensivo, sincero, } \\
\text { mostrava vontade de ajudar }\end{array}$ & 0 & 3 & 1 & 5 & 0 & 0 \\
\hline $\begin{array}{l}\text { 7. Reconhecimento (atenção } \\
\text { dispensada) }\end{array}$ & 0 & 0 & 1 & 0 & 0 & 0 \\
\hline 8. Ser responsável & 0 & 0 & 0 & 0 & 4 & 1 \\
\hline $\begin{array}{l}\text { 9. Sociabilidade (atitude extro- } \\
\text { vertida, boas maneiras - bom } \\
\text { trato) }\end{array}$ & 0 & 5 & 0 & 0 & 2 & 0 \\
\hline $\begin{array}{l}\text { 10. Era quieto e fazia todas as } \\
\text { atividades }\end{array}$ & 0 & 0 & 0 & 0 & 1 & 0 \\
\hline $\begin{array}{l}\text { 11. Grande avanço na autofor- } \\
\text { mação }\end{array}$ & 0 & 0 & 0 & 0 & 0 & 1 \\
\hline $\begin{array}{l}\text { Total de Alunos que realizaram } \\
\text { escolhas }\end{array}$ & 10 & 13 & 8 & 13 & 10 & 13 \\
\hline
\end{tabular}

Fonte: Os autores.

A Tabela 6 nos permite acompanhar os motivos das escolhas dos participantes, no início e no final da observação, nas três situações desta pesquisa. Os participantes solitários e isolados presentes no início do curso, e que não fizeram escolhas, não foram incluídos na Tabela 6. Contudo, suas justificativas para a não-escolha serão incluídas ao final da análise de cada situação, de forma que, para fins estatísticos, consideramos os alunos que fizeram 
escolhas e as justificaram. Como se pode perceber do quadro, ao final nenhum aluno deixou de escolher e de apresentar justificativa.

\section{Situação Afetiva:}

Início - Destacam os seguintes motivos:

a) A "afinidade/simpatia" entre os participantes aparece em primeiro lugar, com um índice de 50\%.

b) Em segundo lugar, surge o motivo "conhecimento antes do curso" com um índice de $40 \%$.

c) Em terceiro lugar, como motivo de escolha, aparece a "aproximação física" (era da mesma família) com $10 \%$.

d) Dos quatro participantes que não realizaram escolhas, três deles justificaram não terem "afinidade/simpatia" com alguém e o outro disse que como não "conhecia ninguém antes do curso", preferiu não escolher.

Final - Predominam os seguintes critérios:

a) Em primeiro lugar, aparece o motivo "sociabilidade" (atitude extrovertida, boas maneiras, bom trato) com $38 \%$.

b) Em segundo lugar, aparecem "ser compreensivo, sincero e ter vontade de ajudar" e a "competência, experiência" com a mesma percentagem, $23 \%$.

c) Em terceiro lugar, aparece a "afinidade, simpatia" com $15 \%$.

d) Nesse segundo momento, todos os alunos realizaram escolhas e as justificaram.

Percebemos que os motivos das escolhas iniciais estão centrados mais nos aspectos afetivos transferenciais ("afinidade, simpatia" e "conhecimento antes do curso") e que há uma depuração desses motivos após a experiência de grupo com uma concentração maior na "sociabilidade". Ao mesmo tempo, parece existir maior objetividade nos julgamentos, na percepção do "outro", considerando-se o desaparecimento das categorias "conhecimento antes do curso" e "aproximação física", e o aparecimento dos motivos "ser compreensivo, sincero e ter vontade de ajudar" e "competência, experiência".

Comparando a situação Inicial e a Final, por meio do Teste de Wilconxon, percebe-se a diferença significativa $\mathrm{p}-0,05$.

\section{2) Situação intelectual:}

Início - Destacam os seguintes motivos:

a) O número de justificativas de "competência, experiência" iguala-se ao de "afinidade, simpatia" como motivo das escolhas dos participantes, sendo a percentagem de $25 \%$ para cada um.

b) Os outros $50 \%$ dos motivos das escolhas se dividem entre "Status" (idade, mesmo nível escolar); "Conhecimento antes do curso" (convivência antes do curso); "Compreensivo, sincero, mostrava vontade de ajudar" e "Reconhecimento" (atenção dispensada). 
c) Os seis participantes que não escolheram alguém justificaram que os colegas não tinham "competência" para ajudá-los a resolver as questões envolvendo os estudos.

Final - Predominam os seguintes critérios:

a) "Competência, experiência com 54\%.

b) "Compreensivo, sincero, mostrava vontade de ajudar", com 38\%.

c) Status" (mesmo nível escolar"), com $8 \%$.

Constatamos também o aumento de objetividade no julgamento, uma vez que os critérios adotados apontam para um decréscimo das escolhas afetivas transferenciais, enquanto a maioria dos alunos elege como critério final a "Competência, experiência". Isso significava não só saber do assunto (cognição), mas demandava experiência (habilidades interpessoais, afetivas etc.), o que não dissocia o afeto da cognição, mas introduz aspectos menos transferenciais para realizar as suas escolhas.

Comparando a situação Inicial e a Final, por meio do Teste de Wilconxon, percebe-se diferença significativa $0,02<\mathrm{p}<0,05$.

\section{3) Situação funcional:}

Início - Destacam os seguintes motivos:

a) "Ser responsável", com $40 \%$.

b) "Afinidade, simpatia" e "Sociabilidade" com a mesma percentagem, 20\%.

c) Os quatro alunos que não realizaram escolhas justificaram que não tinham "afinidade" com alguém.

Final - Predominam os seguintes critérios:

a) "Competência, experiência", com $84 \%$.

b) "Ser responsável" e "Grande avanço na autoformação", com $8 \%$ cada.

A evolução notada nas situações anteriores aparece também nesta situação. Identificamos a presença de critérios menos afetivo-transferenciais e a objetividade marcada pelas escolhas centradas na "competência e experiência". Ou seja, além da responsabilidade, se espera um líder que congregue competências (conhecimentos, habilidades e atitudes), demonstrando isto no comportamento prático (experiência).

Ao final das três situações estudadas, comparando a categoria "afinidade, simpatia", que representa o nível mais intenso da influência dos aspectos afetivo-transferenciais, e a categoria "competência, experiência", que demonstra maior grau de objetividade nos julgamentos, constatamos uma redução da primeira categoria, com $15 \%$ na situação afetiva e ausente na situação intelectual. Já a segunda categoria aparece com $23 \%$ na situação afetiva e atinge ao máximo (84\%) na situação funcional. Com isso, podemos verificar o quanto os julgamentos passaram a ser realizados de forma mais objetiva e menos transferencial.

Comparando a situação Inicial e a Final, por meio do Teste de Wilconxon, percebe-se diferença significativa $p=0,05$. 


\section{ÍNDICE DA FUnÇ̃̃o "Tele" GruPal}

No Sociograma a seguir, todos os aspectos da rede sociométrica do grupo são representados graficamente, quanto à natureza das eleições, à direção das eleições, conforme os gráficos anteriores. Contudo, neste momento, destacamos no gráfico apenas as congruências das eleições (mutualidades), ou seja, quando duas pessoas do grupo se elegem mutuamente de forma positiva (escolhem-se mutuamente). Em termos sociométricos, a presença desse tipo de escolha indica que há uma "relação congruente" entre elas, ou seja, revela a presença do fator "Tele" e, por conseguinte, a saúde das relações estabelecidas no âmbito grupal, conforme destaca Moreno (1992, 1994a, 1994b). Este será o nosso foco de análise com talsociograma.

As congruências são representadas no gráfico a seguir, pela convergência das setas (pontas duplas) que indicam as mútuas eleições da mesma natureza (positivas).

Figura 5: Sociograma da Função "Tele".

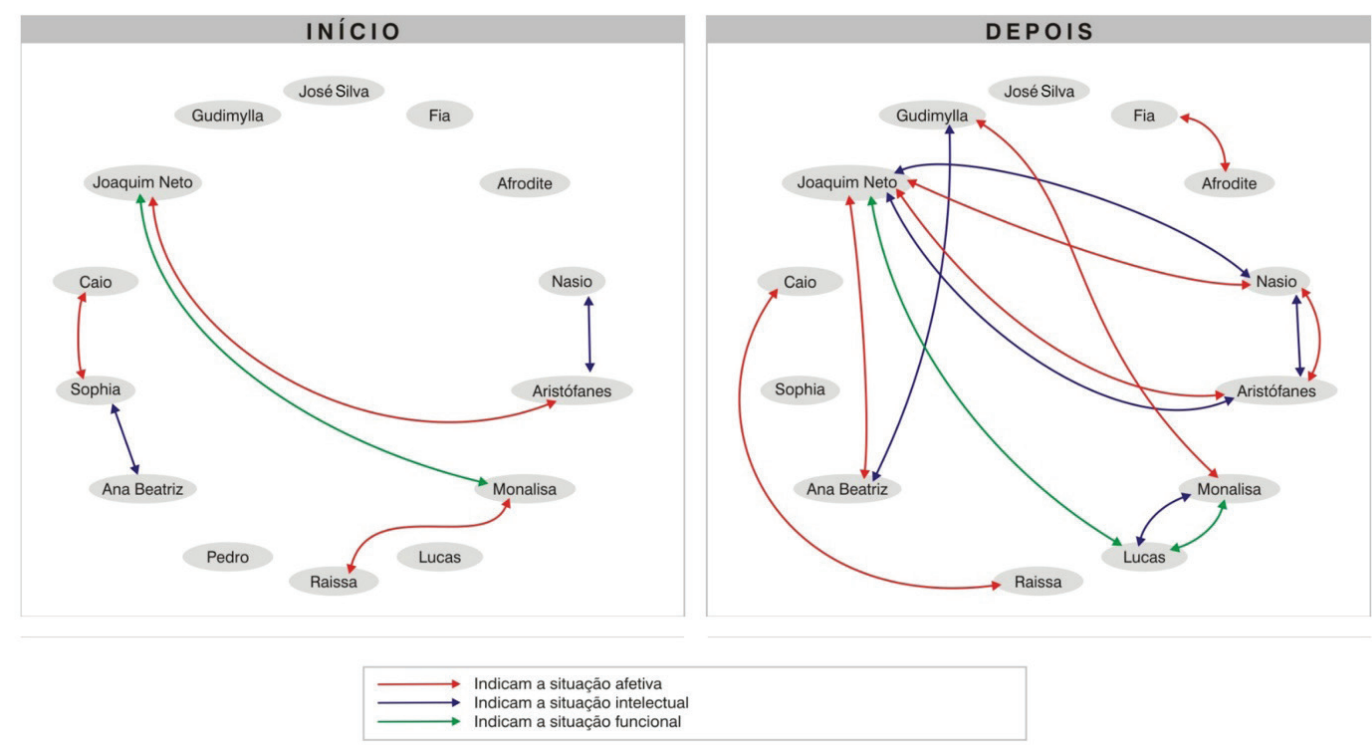

Fonte: Os autores.

Assim, diante do sociograma em questão, podemos observar que de todas as eleições positivas feitas pelos membros do grupos e formam:

Antes: Seis relações congruentes;

Depois: Treze relações congruentes.

Como o Teste Sociométrico, utilizado nesta pesquisa, permitia a cada um dos treze participantes emitir três eleições positivas (afetiva, intelectual, funcional), e uma vez que cada relação congruente envolve duas pessoas, então em um grupo com quatorze componentes o número máximo possível de tais relações é calculado por 14 × 3 / 2, totalizando 
21 relações. Ao final, com apenas 13 componentes, o número máximo de relações foi estabelecido pela fórmula $\mathrm{N}=[(13 \times 3)-1] / 2$, em que $\mathrm{N}$ é o número máximo de relações congruentes virtualmente possíveis. No caso referido, é preciso diminuir uma unidade do total de 39, já que restaria um componente com apenas duas relações congruentes. Assim, com base nesses dados, e seguindo as orientações de Bustos (1979), podemos calcular o índice de relações télicas alcançadas pelo grupo nas duas situações de avaliação. Para tanto, basta calcular o percentual de relações télicas apresentadas pelo grupo em ambos os momentos, Início (6) e Final (13), considerando respectivamente, o número máximo de relações congruentes no Início (21) e no Final (19). Verifica-se, desse modo, que o "índice télico grupal" apresentado nesta pesquisa foi de $28,6 \%$ no Início, e $68,4 \%$ depois da observação. Sintetizamos essas informações na tabela a seguir:

Tabela 6: Frequência de relações congruentes e índice télico grupal.

\begin{tabular}{c|c|c}
\hline & $\begin{array}{c}\text { Frequência } \\
\text { de Relações } \\
\text { Congruentes }\end{array}$ & $\begin{array}{c}\text { Índice Télico } \\
\text { Grupal }\end{array}$ \\
\hline INÍCIO & 6 & $28,6 \%$ \\
\hline FINAL & 13 & $68,4 \%$ \\
\hline
\end{tabular}

Considerando que as relações congruentes indicam a presença do fator Tele e, por conseguinte, a saúde da relação grupal, podemos indicar que houve um aumento na saúde da rede de relações que se estabeleceu entre os membros do grupo, uma vez que o "índice télico grupal" foi bem maior no segundo momento da avaliação. Esse índice ainda indica que o grupo, nesse momento da pesquisa, encontra-se em processo de organização interna, principalmente se considerarmos o índice télico virtualmente ideal de $100 \%$. Isso é corroborado pelos critérios definidos por Bustos (1979), quando estabelece que um grau inadequado de "índice télico grupal" varia de $0 \%$ a $30 \%$,e um grau adequado de "índice télico grupal" (50\% a 70\%). Desse modo, as relações grupais identificadas neste estudo saíram do nível inadequado transferencial para um nível adequado de construção de vínculos, pautados nos aspectos saudáveis da personalidade dos envolvidos no grupo.

A natureza dos motivos das escolhas realizadas ao final da observação também nos aponta a redução das transferências, o que nos permite inferir a grande possibilidade de um aumento gradativo do índice télico das relações ao longo do curso.

\section{CONSIDERAÇõES FINAIS: TECENDO "REDES SOLIDÁRIAS"}

Uma análise geral dos dados do questionário sociométrico nos permite dizer que, no início do trabalho, a rede de relações presentes não possibilita classificar a junção dos indivíduos como um grupo, seria mais o que na literatura especializada em grupo se classifica de "agrupamento". Isto quer dizer que os participantes estavam agrupados, colocados juntos, sem necessariamente constituírem um grupo propriamente dito.

160 Comunicações $\mid$ Piracicaba $\mid$ v. $25 \mid$ n. $2 \mid$ p. 137-166| maio-ago. 2018 
Ao final da intervenção, começa a emergir uma concepção de grupo como uma "rede de solidariedade" (SOUZA SANTOS, 2000) que tem consciência de algo em comum e cuja ação é socialmente expressiva e voltada para a formação humana nas suas múltiplas dimensões. Percebemos a possibilidade de surgir no tecido social, com base nos laços de solidariedade, pertencimento e ciclo do dom (dar, receber e retribuir), uma nova configuração grupal. Tal configuração pode possibilitar a superação dos entraves relacionais por meio de uma lógica das relações interpessoais, apoiada nos valores humanos e em uma cultura de paz. Isto pode nos oferecer reflexões sobre o significado das novas perspectivas de participação nos interesses coletivos no campo educacional.

Os resultados encontrados neste estudo encontram ressonância direta com os desenvolvidos por Carreteiro e Sudbrack (1999) e Sudbrack (1996, 1998, 2000) que, estudando crianças e adolescentes em situação de risco psicossocial, definem as redes sociais como uma nova metodologia de prevenção à marginalização e à drogadição entre adolescentes de famílias de baixa renda. Percebemos também que tais resultados estão alinhados com os estudos mais recentes de Hurtado; Leiva e Cárdenas-Villalobos(2018), que reforçam o uso de sociogramas na escola para a melhoria da convivência, o de Nunes (2017), quando destaca a relação do status sociométrico e a avaliação das interações sociais em crianças do ensino fundamental 1, o de Avramidis, Strogilos, Aroni; Kantaraki (2017), ao apontar o uso de técnicas sociométricas para a avaliação do impacto social de inclusão; e o de Bartholomeu; Montiel; Pessotto (2011), quando descrevem a relação entre sociometria e habilidades sociais em alunos do ensino médio.

Os resultados do teste sociométrico associados à observação participante nos permitiram reconhecer a presença das seguintes características no grupo em questão após a intervenção:

a) Os participantes estavam em maior contato entre si, ou seja, houve um aumento das relações "face a face", indicando uma ampliação do contato interpessoal. Isto pode ser percebido pela redução dos subgrupos, ausência de isolados e solitários e aumento das lideranças. Assim podemos falar no surgimento de um grupo.

b) Houve um aumento significativo das interações entre os participantes; o grupo, do ponto de vista dinâmico, resulta da interação de seus membros, o que nos permite falar da presença de um grupo ao final da observação. A intensa rede de relação pode ser percebida pelo alto nível de influência que os membros passaram a ter uns sobre os outros, de forma que mesmo quem não influencia, acaba sendo influenciado a participar de alguma maneira na configuração grupal.

c) Tinham metas coletivas, ou seja, o grupo tinha uma razão de existir, algo que congregava os interesses e a ação de seus membros em torno de objetivos comuns. Esses objetivos estavam bastante explícitos e definidos. Contudo, como ocorre em todo grupo que se reúne para atingir metas de ordem psicológica e social, há uma intensa complexidade, sendo essas metas afetadas pelas dinâmicas vivenciadas ao longo do grupo, sem, todavia, perderem o objetivo do crescimento.

d) Interdependem na busca de suas metas, ou seja, mais que apenas interagir ou ter 
metas em comum, os membros do grupo, na verdade, dependiam, ao menos em algum grau, uns dos outros, para atingir os seus objetivos. Os trabalhos ou as atividades realizados pelo grupo envolviam os participantes de tal modo que os resultados dependiam dos esforços coordenados de todos os seus membros, e a deficiência ou a eficiência da ação de cada um refletia na atuação dos outros e no resultado final obtido pelo grupo.

e) Constituíam uma entidade comum, uma totalidade, um sistema, um todo orgânico que era mais que a soma de seus membros ou da interação entre eles. Nesse sentido, podemos dizer que o grupo constituía uma entidade, algo com a qualidade de ser uma unidade emergente da diversidade de seus membros, e não a simples justaposição de fragmentos independentes.

Em uma perspectiva mais abrangente, o grupo investigado constituiu-se em um espaço de pertencimento, de autoafirmação e formação. Ou seja, no cotidiano das suas relações grupais os atores/protagonistas passaram a se formar, na medida em que as experiências de deslocamento permitiam ampliar as formas de ser e conviver.

$\mathrm{O}$ aprender a viver juntos apontado pela experiência, nos ajuda a pensar uma pedagogia que promova o respeito pelos valores do pluralismo, da compreensão mútua e da solidariedade. Como indica Gadotti (2000), essa dimensão de solidariedade e convivência é necessária às novas perspectivas em educação. Assim, a tarefa da educação dentro de uma perspectiva solidária e de convivência é, pois, transmitir conhecimentos sobre a diversidade humana, bem como, mostrar e levar as pessoas a se conscientizar acerca das interdependências entre todos os seres humanos.

\section{REFERÊNCIAS}

AFONSO; SILVA; ABADE. O processo grupal e a educação de jovens e adultos. Psicologia em Estudo, Maringá, v. 14, n. 4, p. 707-715, out./dez. 2009.

AVRAMIDIS, E., STROGILOS, V., ARONI, K., KANTARAKI, C. T. Using sociometric techniques to assess the social impacts of inclusion: Some methodological considerations. Educational Research Review, 20, 2017, p.68-80.

BARTHOLOMEU, D., MONTIEL, J. M., PESSOTTO, F. Sociometria e habilidades sociais em alunos do ensino médio. Estudos Interdisciplinares em Psicologia, Londrina, v. 2, n. 2, p. 211-228, dez. 2011.

BASTOS, A.B.B.I. A técnica de grupos-operativos à luz de Pichon-Rivière e Henri Wallon.Psicol inf. São Paulo, v. 14, n. 14, out. 2010. Disponível em http://pepsic.bvsalud. org/scielo.php?script=sci arttext\&pid $=\mathrm{S} 1415-88092010000100010 \& \operatorname{lng}=\mathrm{pt} \& \mathrm{nrm}=$ iso . Acesso em 20 out. 2015.

BERGAMI, C. W. Liderança: administração do Sentido. São Paulo: Atlas, 1994. 
BITTENCOURT, I. G.; LIMA, Á. R. de; GESSER, M. O trabalho em grupo como dispositivo para ressignificação da queixa escolar. Gerais, Rev. Interinst. Psicol. Belo Horizonte, v. 10, n. 2, p. 194-203, dez. 2017. Disponível em <http://pepsic.bvsalud.org/ scielo.php?script $=$ sci_arttext\&pid=S1983-82202017000200005\&lng $=$ pt\&nrm=iso. Acessos em 5 jun. 2018.

BRASIL. Lei de Diretrizes e Bases da Educação: Lei no ${ }^{\circ}$ 9.394/96, 24 de dez. 1996. Estabelece as diretrizes e bases da educação nacional. Brasília, 1998.

BUSTOS, D. M. O Teste Sociométrico: fundamentos, técnicas e aplicações. São Paulo: Brasiliense, 1979.

CARRETEIRO, T. C.; SUDBRACK, M. F. O. Drogues, jeunesse et exclusion sociale au Bésil. In: RAGI, T. (Org.). Agora Débats. Paris: Institut National de la Jeunesse et de l'Education Populaire, 1999, p.94-106.

CASASSUS, J. Fundamentos da educação emocional. Brasília: Iber livros, 2009.

CRESWELL, J. W. Projeto de pesquisa: métodos qualitativo, quantitativo e misto. Porto Alegre: Artmed, 2010.

CUNHA, D. P. Fundamentos Multiparadigmáticos da Formação Humana: contribuições dos paradigmas transpessoal, intercultural e da espiritualidade para a educação no Brasil e na França. Tese (Doutorado em Educação) - Centro de Educação, UFPE, Recife, 2017.

DELORS, J. Educação: um tesouro a descobrir. Relatório para a UNESCO da Comissão Internacional sobre educação para o século XXI, 8. ed. São Paulo: Cortez; Brasília: MEC: UNESCO, 2010.

DEL PRETTE, A.; DEL PRETTE, Z. A. P. Um sistema de categorias de habilidades sociais educativas. Paidéia, 18 (41), 517-530, 2008.

DEL PRETTE, A.; DEL PRETTE, Z. A. P. Pais e professores contribuindo para o processo de inclusão: que habilidades sociais educativas apresentar? In: ALMEIDA, M. A.; MENDES, E. G.; HAYASHI, M. C. P. I. (Org.). Temas em Educação Especial: conhecimentos para fundamentar a prática. Araraquara: Junqueira \& Marin, 2008b, p. 239-254.

. Psicologia das relações interpessoais: vivências para o trabalho em grupo. Petrópolis: Vozes, 2001.

DOURADO, O. A qualidade da educação: Perspectivas e desafios Cad. Cedes, Campinas, vol. 29, n. 78, p. 201-215, mai./ago. 2009.

FERREIRA, A. L. Do entre-deux de Merleau-Ponty à atenção/consciência do budismo e da abordagem transpessoal: a busca de uma pedagogia direcionada para integralidade da formação, 2007. Tese (Doutorado em Educação) - Centro de Educação, UFPE, Recife, 2007. 
FREITAS, A. S. Fundamentos para uma Sociologia Crítica da Formação Humana, 2005. Tese (Doutorado em Ciências Sociais) - UFPE, Recife, 2005.

FREUD, S. Psicologia de grupo e análise do ego. Rio de Janeiro: Imago, 1976.

GADOTTI, M.Perspectivas atuais em educação. Porto Alegre: Artmed, 2000.

GIL, A. C. Métodos e técnicas de pesquisa social. São Paulo: Atlas, 1995.

HURTADO, C. U., LEIVA, V. L, CÁRDENAS-VILLALOBOS, J.P. El uso de sociogramas em laescuela para lamejora de laconvivencia: um estúdio em escuelas chilenas. Perfiles Educativos, vol. XL, n. 160, 2018, p.83-100.

LEWIN, K. Problemas de dinâmica de grupo. São Paulo: Cultrix, 1989.

MACEDO, A. B. de; MEDINA, G. B. K.O que dizem os estudos brasileiros sobre o relacionamento interpessoal no ambiente escolar: uma revisão de literatura Pluralidades em Saúde Mental, Curitiba, v. 6, n. 1, p. 93-114, jun./jul. 2017.

MAILHIOT, G. B. Dinâmica e Gênese dos Grupos: Atualidades e descobertas de Kurt Lewin. Petrópolis, Rio de Janeiro: Editora Vozes 2013.

MALHEIROS, B. T. Metodologia da Pesquisa em Educação. Rio de Janeiro: LTC, 2011. MINAYO, M. C. de S. (Org.). Pesquisa social: teoria, método e criatividade, 29. ed. Petrópolis, RJ: Vozes, 2010.

MORENO, J. L. Psicoterapia de Grupo e Psicodrama. São Paulo: Mestre Jou, 1974. . Psicodrama. São Paulo: Cultrix, 1991.

. Quem Sobreviverá? Fundamentos da Sociometria, Psicoterapia de grupo e Sociodrama (vol. I). Goiânia: Dimensão Editora, 1992.

. Quem Sobreviverá? Fundamentos da Sociometria, Psicoterapia de Grupo e Sociodrama (vol. II). Goiânia: Dimensão Editora, 1994a.

. Quem Sobreviverá? Fundamentos da Sociometria, Psicoterapia de Grupo e Sociodrama (vol. III). Goiânia: Dimensão Editora, 1994b.

MOSCOVICI, F. Desenvolvimento Interpessoal: treinamento em grupo, 7 ed. Rio de Janeiro: José Olympio, 2012.

. Equipes dão Certo: a multiplicação do talento humano 9a edição. Rio de Janeiro:

Editora José Olympo, 2004.

NAFFAH NETO, A. Psicodrama: Descolonizando o Imaginário. São Paulo: Brasiliense, 1979.

NUNES, M. F. Status sociométrico e a avaliação das interações sociais em crianças do ensino fundamental 1. Dissertação (Mestrado em Psicologia) - USP, São Paulo, 2017.

PAIXÃO, L. E. S.; MUCHON, D.; SOLOMON, D. V. Evolução das relações interpessoais 
e do sistema de valores através do questionário sociométrico. In: WEIL, P. et al. Dinâmica de grupo e desenvolvimento em relações humanas. Belo Horizonte: Itatiaia, 2002, p. 164-189.

RODRIGUES, N. Educação: da formação humana à construção do sujeito ético. Educação \& Sociedade. Campinas, n. 76, p. 232-257, out. 2001.

ROGERS, R. C. Grupos de Encontro. São Paulo: Martins Fontes, 1978.

ROSIN-PINOLA, A. R.; DEL PRETTE, Z.A.P. Inclusão escolar, formação de professores e assessoria baseadaem habilidades sociais educativas. Revista Brasileira Educação Especial, Marília, v. 20, n. 3, p. 341-356,jul./set. 2014. Disponível em: http://dx.doi. org/10.1590/S1413-65382014000300003. Acesso em: 20 mai.2017.

ROSIN-PINOLA, A. R.; MARTURANO, E. M.; ELIAS, L. C. dos S.; DEL PRETTE, Z. A. P. Ensinando habilidades sociais educativas para professores no contexto da inclusão escolar.Revista Educação Especial, Santa Maria, v. 30, n. 59, p. 737-750, set./dez. 2017. Disponível em: https://periodicos.ufsm.br/educacaoespecial. Acesso em 10 fev. 2017.

SAVIANI, D.; COSTA, A. C. G.; CASCINO, P. Educador: Novo Milênio, novo perfil? São Paulo: Paulus, 2000.

SEVERINO, A. J.; BAUER, C.Filosofia e formação humana na educação básica. EccoS Revista Científica, n. 39, enero-abril, 2016, p. 11-14 Universidade Nove de Julho São Paulo, Brasil.

SILVA, J. A. P. O uso de dinâmicas de grupo em sala de aula. Um Instrumento de aprendizagem experiencial esquecido ou ainda incompreendido? SABER CIENTÍFICO, Porto Velho, 1 (2): 82- 99, jul./dez., 2008.

SOUZA SANTOS, B. de. A crítica da razão indolente: contra o desperdício da experiência. São Paulo: Cortez Editora, 2000.

SUDBRACK, M. F. O. Abordagem comunitária: uma nova forma de pensar a prevenção do uso indevido de drogas. In: SUDBRACK, M. F. O.; SEIDL, E. M. F.; COSTA, L. F. (Org.). Prevenção do uso indevido de drogas: Diga SIM à Vida, 2. Brasília: CEAD-UnB e SENAD-SGI-Presidência da República, 2000.

. Construindo redes sociais: Metodologia de prevenção à drogadição e à marginalização de adolescentes de famílias de baixa-renda. In: MACEDO, R. M. (Org.). Família e Comunidade: Coletâneas da ANPEPP, 2, 87-113, 1996.

. Situações de risco à drogadição entre crianças e adolescentes no contexto de baixa renda: Os paradoxos e as possibilidades da família. Revista SER Social, 3, 219-293, 1998.

VAZ, G. J. A construção dos sociogramas e a teoria dos grafos.Rev. bras. psicodrama, São Paulo, v. 17, n. 2,p. 67-78, 2009. Disponível em http://pepsic.bvsalud.org/scielo.php?script $=$ sci_arttext\&pid=S0104-53932009000200006\&lng=pt\&nrm=iso. Acesso em 12 mai. 2017. 
VIEIRA-SANTOS, J.; DEL PRETTE, Z. A. P.; DEL PRETTE, A. (2018). Habilidades sociais educativas: revisão sistemática da produção brasileira. Avances em PsicologíaLatinoamericana, 36(1), 45-63. doi: http://dx.doi.org/10.12804/revistas.urosario.edu.co/ apl/a.5069. Acesso em 20 mai. 2017.

WEIL, P. A Dinâmica de grupo e desenvolvimento em relações humanas. Belo Horizonte: Itatiaia, 2002.

\section{Dados dos Autores:}

\section{Aurino Lima Ferreira}

Departamento de Psicologia e Orientações Educacionais do Programa de Pós-graduação em Educação Universidade Federal de Pernambuco (UFPE), Recife/PE - Brasil. aurinolima@gmail.com

\section{Tatiana Lima Brasil}

Mestra em Educação UFPE, Doutoranda em Educação UFPE. Universidade Federal de Pernambuco (UFPE), Recife/PE - Brasil. tatiana.limabrasil@gmail.com

\section{NadJa Maria Acioly-Règnier}

Directrice de thèses Ecole Doctorale 485 - EPIC. UMR 5191 ICAR -Interactions, Corpus, Apprentissage, Représentations)ESPE Université Lyon1, Lyon - França. nadja.acioly-regnier@univ-lyon1.fr

Submetido em: 8-6-2017

Aceito em:12-6-2018 